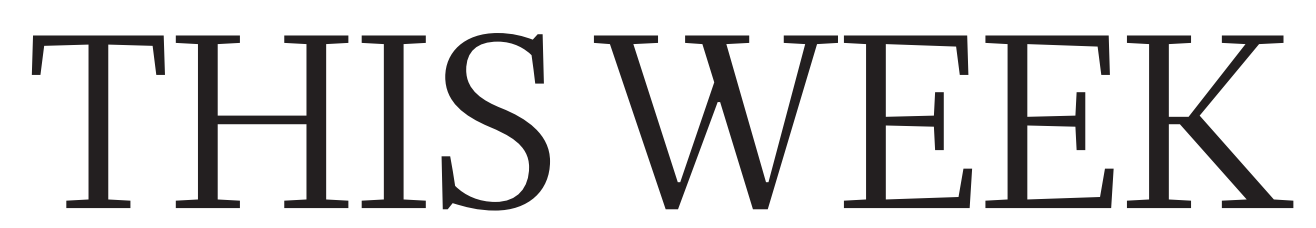

EDITORIALS

FUNDING Acknowledge that research support is a risky business $\mathbf{p . 2 5 6}$
TRIALS 'Post-normal science' could smooth clinical regulation $\mathbf{p . 2 5 7}$
CUCKOO Adult birds repeat the look-alike trick with feathers $\mathbf{p . 2 5 8}$

\title{
Sexism has no place in science
}

\section{The comments about women in the laboratory made by Nobel laureate Tim Hunt are a reminder that equality in science is a battle still far from won.}

$\mathrm{L}$ ast week's incident at a meeting of science journalists in South Korea, at which the British Nobel prizewinner Tim Hunt expressed jaw-dropping and belittling sentiments about women in the laboratory, is focusing minds, once again, on how to make the most of that half of the human population in research.

All involved in science should condemn the comments, which suggested that single-sex labs might be preferable because "girls" tend to fall in love with their male colleagues and cry when criticized.

Hunt - who won the 2001 Nobel Prize in Physiology or Medicine for his work on cell division - said that his remarks were intended to be light-hearted. Following a storm on Twitter and much media coverage, he was asked to step down from various influential roles.

Some public and media analysis of the sorry story has now shifted to argument about whether the punishment fits the crime. In an interview with the Observer newspaper last weekend, Hunt complained that he had been "hung out to dry".

Whether or not the reaction has been fair, his comments and attitudes have become shorthand for the dismaying extent to which sexism still pervades science, and serve as a prompt to discuss the problem.

The problem is worth, once again, stating clearly. In the United States and Europe, around half of those who gain doctoral degrees in science and engineering are women - but barely one-fifth of full professors are women. Women are not invited in significant numbers to sit on the scientific advisory boards of start-up companies. A scientific conference at which half of the keynote speakers are women stands out simply because of that.

The challenge and the consequences of the lack of women in research - especially at senior levels - are expressed in many ways, with worrying persistence. Evidence suggests that too many women encounter patronizing attitudes or harassment in research contexts - whether at work, at academic conferences or in the field. Recent evidence, such as studies of mock hiring exercises, and analysis of grant success rates, authorship assignment and citation counts, suggests that discrimination against women runs deep in the psyches of both genders.

The problem is serious and long-standing. But there are plenty of ways to tackle it. Nature has discussed and promoted them before, and is happy to do so again. Here is a list of measures to consider afresh:

- Recognize and address unconscious bias. Graduate students given grants by the US National Institutes of Health are required to undergo ethics training. Gender-bias training for scientists, for example, would be a powerful way to help turn the tide.

- Encourage universities and research institutions to extend the deadlines for tenure or project completion for scientists (women and men) who take parental leave, and do not penalize these researchers by excluding them from annual salary rises. Many workplaces are happy to consider and agree to such extension requests when they are made. The policy should simply be adopted across the board.

- Events organizers and others must invite female scientists to lecture, review, talk and write articles. And if the woman asked says no - for whatever reason - then ask others. This is about more than mere visibility. It can boost female participation too. Anecdotal reports suggest that women are more likely to ask questions in sessions chaired
"Too many
by women. After acknowledging our own bias

women

encounter

patronizing

attitudes or

harassment

in research contexts." towards male contributors, Nature, for example, is engaged in a continued effort to commission more women in our pages.

- Do not use vocabulary and imagery that support one gender more than another. Words matter. It is not 'political-correctness-gonemad' to avoid defaulting to the pronouns 'him' and 'he', or to ensure that photographs and illustrations feature women.

- In communication and promotional materials, highlight women who have made key contributions to previous work, whether in your own lab or within your research discipline more broadly. - Be aware of the importance of informal settings and social activities to workplace culture, and people's sense of their place within it. Senior scientists can, where possible, make such events inclusive.

The lot of the female scientist in most developed countries is better than it was a few decades ago - a time that forged the thinking and attitudes of many of today's senior scientists. But such attitudes continue to prevent equality. It is right to highlight and protest against examples of explicit and implicit bias - of all types - in research. And it is essential that all involved strive for better.

\section{The right climate}

\section{A Republican US presidential candidate speaks on climate change, but will his party listen?}

U S Senator Lindsey Graham of South Carolina became the ninth contender for the Republican presidential nomination earlier this month. He is a staunch conservative who tends to vote with his party on everything from gun control to health care and foreign policy. He is also the first Republican candidate to squarely address the question of climate change - in a constructive way. During an interview on the CNN news channel on 7 June, Graham highlighted the problem and issued a welcome challenge to his fellow Republicans. 